\title{
INTERRELACIÓN DEL CICLO DE MUDA, EL CICLO OVÁRICO Y EL DESARROLLO EMBRIONARIO EN HEMBRAS DE Cryphiops caementarius MOLINA 1782 (CRUSTACEA, PALAEMONIDAE)
}

\author{
INTERRELATIONSHIP OF MOULT CYCLE, OVARIAN CYCLE AND EMBRYONIC \\ DEVELOPMENT IN FEMALES OF Cryphiops caementarius MOLINA 1782 \\ (CRUSTACEA, PALAEMONIDAE)
}

Walter Reyes Avalos

\begin{abstract}
RESUMEN
El objetivo del presente estudio fue determinar la interrelación del ciclo de muda, ciclo ovárico y desarrollo embrionario en hembras del camarón de río Cryphiops caementarius. Se emplearon 45 hembras ovígeras de $43 \mathrm{~mm}$ de longitud total, y se evaluaron los estados del ciclo de muda, los estados del ovario y los estadios del desarrollo embrionario durante dos ciclos reproductivos sucesivos en el período de baja reproducción (abril - agosto 2010). Los resultados muestran que en todas las hembras ovígeras con ovarios maduros y en aquellas (50\%) con maduración intermedia, hubo interrelación entre el desarrollo embrionario, la maduración ovárica y el ciclo de muda. En cambio, en todas las hembras ovígeras con ovarios inmaduros y en aquellas (50\%) con maduración intermedia, sólo hubo interrelación entre el desarrollo embrionario y el ciclo de muda que culminó con su actual ciclo reproductivo.
\end{abstract}

PALABRAS CLAVE: Ciclo de muda, ciclo ovárico, camarón, Cryphiops caementarius

\begin{abstract}
The aim of this study was to determine the interrelationship of the moult cycle, ovarian cycle and embryonic development in females of the prawn Cryphiops caementarius. Forty-five $43 \mathrm{~mm}$ LT ovigerous females were used, and the states of the moult cycle, the states of the ovary and the embryonic stages were evaluated during two successive reproductive cycles in the low reproductive period (april - august 2010). The results showed that in all ovigerous females with mature ovaries and those with intermediate maturiy (50\%), there was interrelationship among embryonic development, ovarian maturation and molting cycle. Unlike the above, in all ovigerous females with immature ovaries and those (50\%) with intermediate maturity, there was only interrelationship between embryonic development and molt cycle culminating in its current reproductive cycle.
\end{abstract}

KEY WORDS: moult cycle, ovarian cycle, prawn, Cryphiops caementarius

\section{INTRODUCCIÓN}

Para un cultivo comercial se requiere disponer de reproductores maduros durante el año para garantizar una producción continua de postlarvas que permita abastecer a los estanques de engorde de camarón (Lee y Wickins, 1997). Sin embargo, la reproducción de Cryphiops caementarius
Molina 1782 en su ambiente natural es fluctuante; si bien desovan todo el año, existe un pico máximo entre noviembre y marzo (Viacava et al., 1978), de ahí la importancia de manejar los reproductores en cautiverio.

En crustáceos superiores existe una sincronización obligatoria entre reproducción y crecimiento (Sardá,

Dirección de los autores:

Laboratorio de Acuarística. Departamento de Biología, Microbiología y Biotecnología. Facultad de Ciencias. Universidad Nacional del Santa. Av. Universitaria s/n. Urb. Bellamar, Nuevo Chimbote, Ancash (Perú). E-mail: wreyes_avalos@hotmail.com 
1987; Vinuesa et al., 1991; Cavalli et al., 2001), debido a que el ciclo reproductivo, el comportamiento del animal y los procesos metabólicos son afectados por el ciclo de muda (Aiken y Waddy, 1987). En hembras de crustáceos, la serie de eventos del ciclo reproductivo se manifiestan desde la activación de la gametogénesis hasta la eclosión de los embriones (Sardá, 1987), reportándose gasto de energía para la producción de gametos (Sokolowicz et al., 2006). En el ciclo de muda, los procesos metabólicos y morfológicos del tegumento determinan los estados de postmuda, intermuda y premuda, entendiéndose como muda el proceso fisiológico y bioquímico, y como ecdisis la eliminación completa de antiguo exoesqueleto por parte del animal, para ser remplazado por otro nuevo (Aiken y Waddy, 1987).

Una estrecha relación entre el ciclo de muda y la maduración del ovario sucede en Macrobrachium rosenbergii (Damrongphol et al., 1991), Pleoticus muelleri (Díaz et al., 2003) y Emerita asiatica (Gunamalai et al., 2004). Por otro lado, la presencia de hembras ovígeras con ovarios maduros es reportada en Crangon crangon (Spaargaren y Haefner, 1994), Palaemon xiphias (Guerao et al., 1994), Exopalaemon modestus (Oh et al., 2002), M. olfersi (Mossolin y Bueno, 2002), M. amazonicum (Sampaio et al., 2007) y Atya scabra (Almeida et al., 2010). En el camarón C. caementarius no se conocía esta relación; por ello, determinarla resulta útil para seleccionar hembras con diversos fines, como estudios reproductivos, fisiológicos, mejoramiento genético, entre otros.

El camarón $C$. caementarius tiene amplia distribución latitudinal en los ríos de la costa peruana y soporta una pesquería comercial (Amaya y Guerra, 1976; Yépez y Bandín, 1997). De su biología reproductiva se ha descrito la formación de gametos, la talla de primera madurez sexual (Lip, 1976), el ciclo reproductivo (Viacava et al., 1978), el desarrollo embrionario (Vegas et al., 1981; Reyes et al., 2009) y el desarrollo larval (Morales et al., 2006). Por consiguiente, dada la importancia de este tipo de recurso, el objetivo del presente trabajo fue determinar la interrelación del ciclo de muda, el ciclo ovárico y el desarrollo embrionario en hembras del camarón de río $C$. caementarius mantenidas en condiciones de laboratorio.

\section{MATERIALES Y MÉTODOS}

Se utilizaron 45 hembras ovígeras de $C$. caementarius de 43,2 $\pm 1,3 \mathrm{~mm}$ LT (escotadura post orbital a extremo posterior del telson), capturadas del río Lacramarca (0907'70'S - 78 34'20' W, Provincia del Santa, Departamento de Ancash, Perú), durante el período de baja reproducción (abril - agosto 2010), las cuales fueron transportadas al laboratorio e identificadas según Méndez (1982). Los camarones fueron aclimatados durante una semana en acuarios de $55 \mathrm{l}$ (0,60 m de largo; 0,31 m de ancho; 0,35 m de alto; con área de $0,186 \mathrm{~m}^{2}$ ), colocándose refugios de tubos PVC de $1^{\prime \prime}$ para disminuir la interacción. Otros acuarios de iguales dimensiones fueron acondicionados dividiéndolos con malla plástica en tres compartimentos de $620 \mathrm{~cm}^{2}$ cada uno, para albergar un camarón por compartimento.

Los estados de madurez ovárica fueron determinados macroscópicamente, observando a simple vista el ovario a través del exoesqueleto del cefalotórax, teniendo en cuenta las descripciones de Viacava et al. (1978) y Moreno et al. (2012); sin embargo, por razones prácticas se consideraron hembras inmaduras (estados I y II), en maduración intermedia (estado III) y maduras (estado IV).

Los estados y subestados del ciclo de muda fueron determinados por observación microscópica de los exopoditos de los urópodos, según Reyes y Luján (2003), considerándose los estados y subestados de postmuda temprana $A\left(A_{1}\right.$ y $\left.A_{2}\right)$, postmuda tardía $B\left(B_{1}\right.$ y $\left.B_{2}\right)$, intermuda $C$ y los estados y subestados de premuda temprana $\left(\mathrm{D}_{0} \mathrm{y} \mathrm{D}_{1}\right.$, con tres divisiones $\left.\mathrm{D}_{1}{ }^{\prime}, \mathrm{D}_{1}{ }^{\prime \prime} \mathrm{y} \mathrm{D}_{1}{ }^{\prime \prime \prime}\right)$, y premuda tardía $\left(\mathrm{D}_{2}\right.$ y $\left.\mathrm{D}_{3}\right)$, culminando con la ecdisis (E). No se consideró el estado $\mathrm{D}_{4}$ por la dificultad de observarlo. Además, después de cada ecdisis se revisaron los pleópodos para observar la presencia o ausencia de setas ovígeras.

Los estadios del desarrollo embrionario fueron identificados según Reyes et al. (2009), extrayéndose aproximadamente 40 huevos de la parte superficial de la masa embrionaria. Las observaciones de la condición de la muda, del ovario y de los embriones de las hembras fueron realizadas tres veces por semana.

Los camarones fueron alimentados con balanceado comercial (Nicovita $\left.{ }^{\circledR}\right)$ para camarón de mar $(25 \%$ de proteína total). El alimento administrado correspondió al $3 \%$ de la biomasa total y se suministró dos veces al día (08:00 y 18:00h) durante seis días cada semana. Los acuarios fueron limpiados diariamente y el agua (30\%) fue cambiada cada semana. La temperatura y el oxígeno del agua fueron medidos con un oxímetro digital $( \pm$ $0,1{ }^{\circ} \mathrm{C}, \pm 0,01 \mathrm{mg} \mathrm{l}^{-1}$, marca YSI 55) y la alcalinidad 
total y la dureza total según los métodos de Fukushima et al. (1982). Los resultados fueron procesados para obtener frecuencias porcentuales utilizando el programa Microsoft Excel ${ }^{\circledR} 2010$.

\section{RESULTADOS}

Calidad del agua: La calidad del agua varió de manera similar en todos los acuarios, siendo la temperatura de $21,3 \pm 1,4{ }^{\circ} \mathrm{C}$, el oxígeno de $4,54 \pm 1,8 \mathrm{mg} \mathrm{l}^{-1}$, la alcalinidad total de $35 \pm 2 \mathrm{mg} \mathrm{l}^{-1} \mathrm{y}$ la dureza total de $280 \pm 21 \mathrm{mg} \mathrm{l}^{-1}$.

Muda: La duración del ciclo de muda fue de 30,5 días; de las cuales 2,7 días correspondieron al estado A; 6,3 días al estado B; 4,4 días al C y 17,1 días al D; siendo el subestado $\mathrm{D}_{1}$ el de mayor duración (11 días) (Tabla 1). Las hembras que estuvieron en premuda tardía $\left(\mathrm{D}_{2}\right.$ y $\left.\mathrm{D}_{3}\right)$, en proceso de ecdisis y en postmuda temprana (A) no ingirieron alimento balanceado.

Tabla 1. Duración de los estados y subestados del ciclo de muda de hembras ovígeras de Cryphiops caementarius mantenidas en condiciones de laboratorio. Se indica el promedio \pm desviación estándar.

\begin{tabular}{lccc}
\hline \multirow{2}{*}{ Estado y subestados del ciclo de muda } & \multicolumn{2}{c}{ Duración } & \multirow{2}{*}{ Días para la ecdisis } \\
\cline { 2 - 3 } & Días & $\%$ & \\
\hline A. Postmuda temprana & & & 30,5 \\
$A_{1}$ & $1,0 \pm 0,0$ & 3,3 & 29,5 \\
$A_{2}$ & $1,7 \pm 0,2$ & 5,6 & 27,8 \\
B. Postmuda tardía & & & 24,8 \\
$B_{1}$ & $3,0 \pm 0,5$ & 9,8 & 21,5 \\
$B_{2}$ & $3,3 \pm 0,5$ & 10,8 & \\
C. Intermuda & $4,4 \pm 0,4$ & 14,4 & 17,1 \\
D. Premuda & & & 13,7 \\
Premuda temprana & & 11,2 & 8,2 \\
Do & $3,4 \pm 0,5$ & 18,0 & 5,0 \\
$D_{1} D_{1}^{\prime}$ & $5,5 \pm 1,2$ & 10,5 & 2,7 \\
$D_{1}^{\prime \prime}$ & $3,2 \pm 0,8$ & 7,5 & 1,0 \\
$D_{1}^{\prime \prime \prime}$ & $2,3 \pm 0,6$ & & \\
Premuda tardía $^{*}$ & & 5,6 & \\
$D_{2}$ & $1,7 \pm 0,3$ & 3,3 & \\
$D_{3}$ & $1,0 \pm 0,2$ & & \\
\hline
\end{tabular}

$\left(^{*}\right)$ No se consideró el estado $\mathrm{D}_{4}$ por la dificultad de observarla.

Desarrollo ovárico: Las hembras con ovarios inmaduros no mostraron cambios morfológicos macroscópicos evidentes, debido a que el ovario fue pequeño, transparente y en algunos casos de color verde claro, éste fue ubicado debajo del corazón; debido a ello fue observado un amplio espacio transparente en la parte superior y anterior interna del cefalotórax, entre el corazón y el estómago (Figura 1A). Las hembras con ovarios en maduración intermedia se caracterizaron por que el ovario en su crecimiento por debajo del corazón alcanzó hasta la mitad interna del cefalotórax, reduciendo el espacio transparente; en este estado el ovario ya adquiere color marrón granate (Figura 1B). Las hembras con ovario maduro se caracterizaron por que el ovario continuó creciendo hasta ocupar totalmente el espacio interno superior y anterior del cefalotórax, alcanzando la zona de inicio del rostro; el color del ovario siguió siendo marrón granate (Figura 1C).

Desarrollo embrionario: La duración del desarrollo de los embriones portados por $C$. caementarius fue de 23 días variando generalmente entre 2,5 y 3,8 días hasta el estadio 8, pero el estadio 9 duró solamente 1,5 días 35 (Tabla 2). 


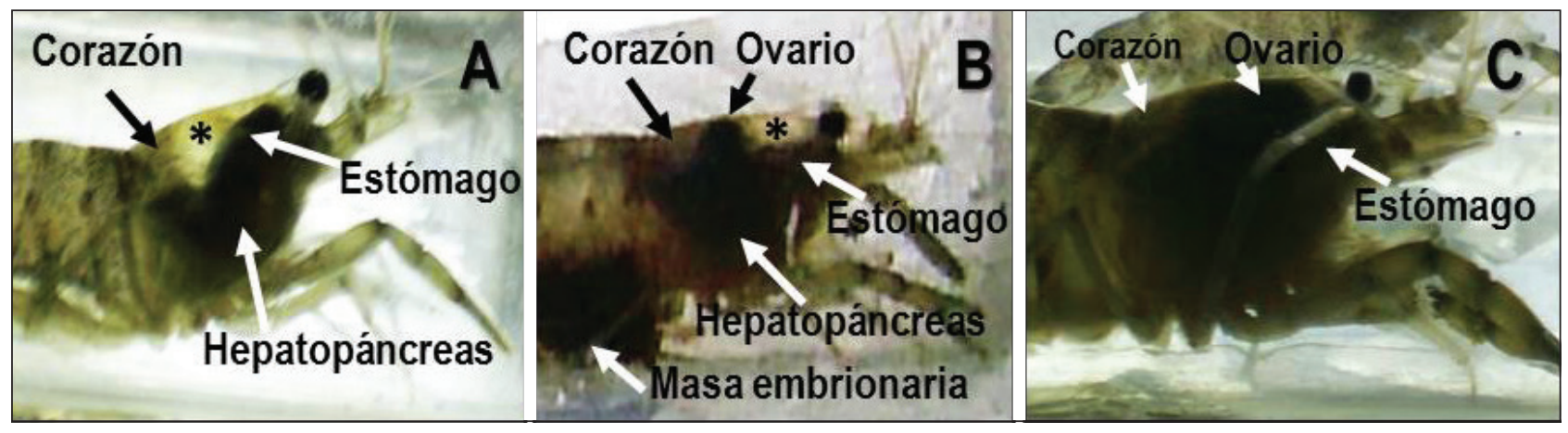

Figura 1. Hembras de Cryphiops caementarius en diferentes estados de desarrollo ovárico: a) Hembra con ovario inmaduro (estados I o II), se observa que el ovario no se nota porque está debajo del corazón pero hay un espacio $\left({ }^{*}\right)$ transparente entre el corazón y el estómago. b) Hembra con ovario en maduración intermedia (estado III), el ovario sale por debajo y delante del corazón y es menor el espacio (*) transparente. c) Hembra con ovario maduro (estado IV), el ovario ocupa toda la parte superior dorsal del cefalotórax.

Tabla 2. Duración de los estadios del desarrollo de embriones (EDE) de hembras ovígeras de Cryphiops caementarius mantenidas en condiciones de laboratorio. Se indica el promedio \pm desviación estándar.

\begin{tabular}{cccc}
\hline \multirow{2}{*}{ EDE } & \multicolumn{2}{c}{ Duración } & $\begin{array}{c}\text { Días para la } \\
\text { eclosión }\end{array}$ \\
\cline { 2 - 3 } & Días & $\%$ & \\
\hline $1-2$ & $3,8 \pm 0,5$ & 16,2 & 23,4 \\
3 & $2,8 \pm 0,5$ & 12,0 & 19,6 \\
4 & $3,2 \pm 0,3$ & 13,7 & 16,8 \\
5 & $3,0 \pm 0,3$ & 12,8 & 13,6 \\
6 & $3,4 \pm 0,2$ & 14,5 & 10,6 \\
7 & $3,2 \pm 0,2$ & 13,7 & 7,2 \\
8 & $2,5 \pm 0,2$ & 10,7 & 4,0 \\
9 & $1,5 \pm 0,2$ & 6,4 & 1,5 \\
\hline
\end{tabular}

Interrelación ciclo de muda y desarrollo embrionario: Todas las hembras ovígeras con embriones en los estadios 1, 2 y 3 estuvieron en muda $\mathrm{AB}$ y $\mathrm{C}$, respectivamente, manteniéndose la mayoría en $\mathrm{C}$ hasta cuando los embriones alcanzaron los estadios 4 (91,5\%) y $5(71,2 \%)$. Cuando los embriones avanzaron al estadio 6 , el 66,7\% estuvieron en premuda $\mathrm{D}_{0}$ y cuando alcanzaron los estadios 7 y 8 , el $77,3 \%$ y el $69,6 \%$, respectivamente, estuvieron en premuda $\mathrm{D}_{1}^{\prime}$ (Figura 2). En estadio 9 y un día antes de la eclosión de embriones 36 las hembras en $\mathrm{D}_{1}{ }^{\prime \prime}(55,6 \%)$ fueron más frecuentes que aquellas en $\mathrm{D}_{1}^{\prime \prime \prime}(25,9 \%)$, en $\mathrm{D}_{1}{ }^{\prime}(14,8 \%)$ y en un solo caso en $\mathrm{D}_{3}(3,7 \%)$ (Figura $3 \mathrm{~A}$ ), ocurriendo la ecdisis post eclosión a los 6, 3, 9 y 2 días, respectivamente (Figura 3B).
Interrelación ciclo ovárico y desarrollo embrionario: Hasta el estadio 6 del desarrollo de los embriones, las hembras ovígeras estuvieron con ovarios inmaduros; sin embargo, a partir del embrión en estadio 7 se pudo evidenciar cuatro grupos de hembras: En el primer grupo, las hembras ovígeras con ovarios inmaduros permanecieron en este estado hasta la eclosión de sus embriones. En el segundo grupo, que correspondió al $50 \%$ del total de las hembras ovígeras con ovarios en maduración intermedia, mantuvieron el mismo estado del ovario hasta eclosión de sus embriones. En ambos grupos, la siguiente muda post eclosión fue una muda regular. En el tercer grupo de hembras, que correspondió al otro 50\% de hembras ovígeras con ovarios en maduración intermedia, la condición ovárica fue la misma que las del segundo grupo, pero con la diferencia de que la siguiente muda post eclosión fue una muda pre-apareamiento. En el cuarto grupo, las hembras ovígeras continuaron madurando hasta alcanzar el estado de ovario maduro conforme avanzó el desarrollo de sus embriones de la masa ovígera (Figura 4) y realizaron muda pre-apareamiento después de la eclosión de sus embriones.

Interrelación ciclo de muda y ciclo ovárico: La mayor parte de las hembras con ovarios inmaduros estuvieron en muda C $(17,8 \%)$ y D $(73,4 \%)$ y en menor proporción en $\mathrm{AB}(8,9 \%)$ y en $\mathrm{D}_{3}(4,1 \%)$. En cambio, casi todas las hembras ( $94 \%$ ) con ovarios en maduración intermedia estuvieron en estado de muda $\mathrm{D}$ y dentro de ésta la mayoría en $\mathrm{D}_{1}(62,6 \%)$. Las hembras con ovarios maduros estuvieron en $D_{1}(66,6 \%)$, en $D_{2}(11,1 \%)$ y en $\mathrm{D}_{3}(22,2 \%)$ (Figura 5). 


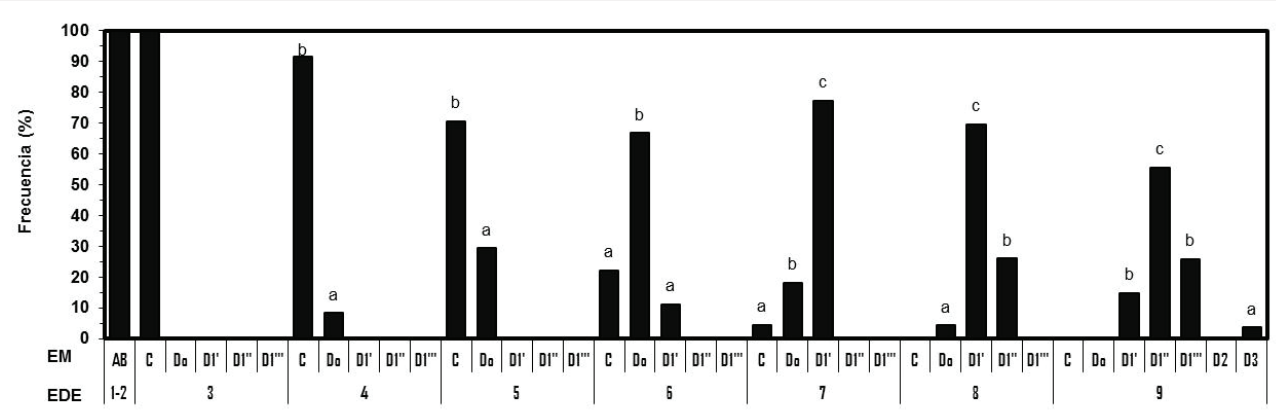

Figura 2. Frecuencia porcentual de la relación entre los estadios del ciclo de muda (EM) y los estadios del desarrollo embrionario (EDE) de hembras ovígeras de Cryphiops caementarius mantenidas en condiciones de laboratorio.
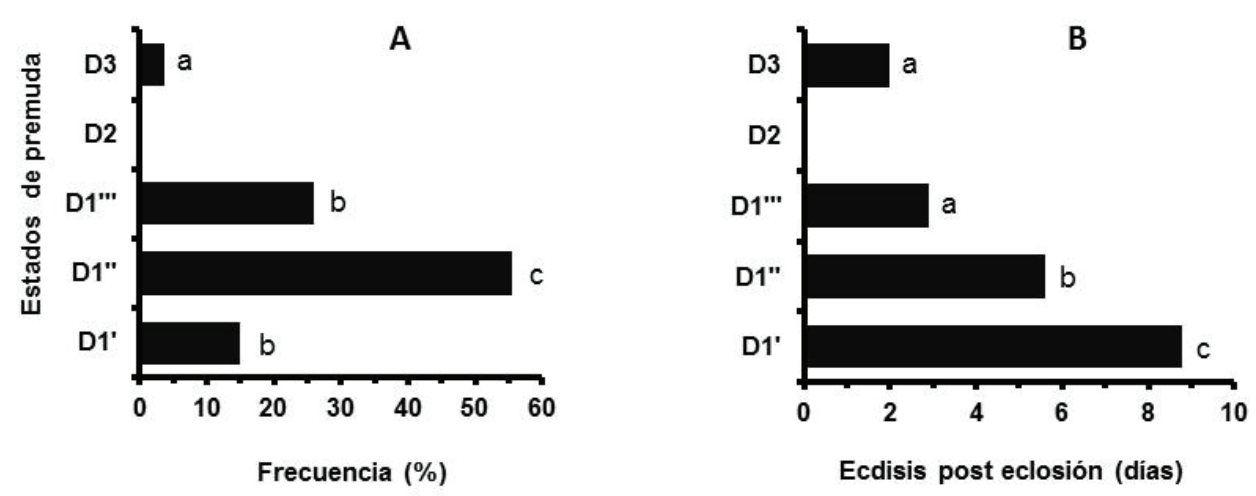

Figura 3. Estados de premuda de hembras de Cryphiops caementarius: a) Frecuencia porcentual un día antes de la eclosión de embriones. b) Duración de la ecdisis post eclosión.

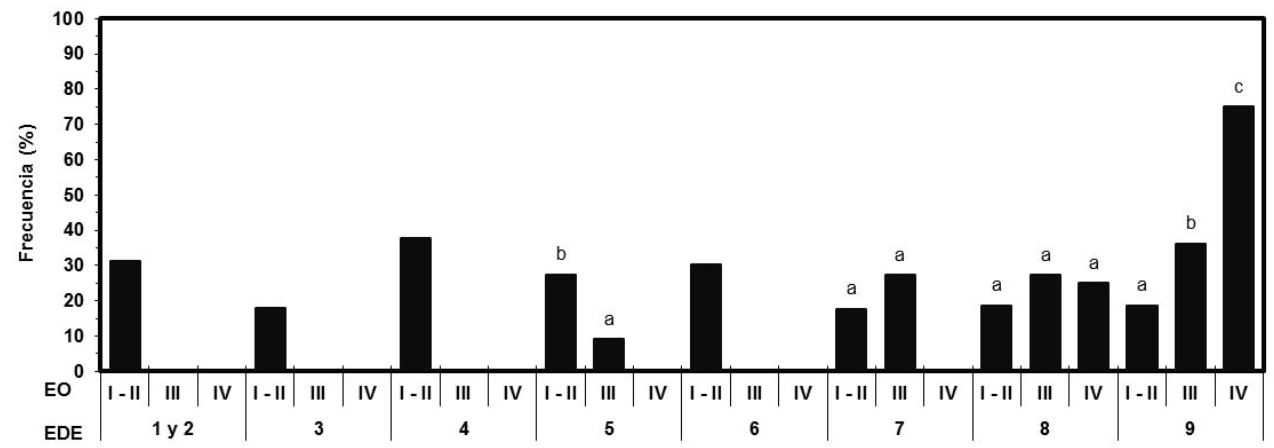

Figura 4. Frecuencia porcentual de la relación entre los estados de maduración del ovario (EO) y los estadios del desarrollo embrionario (EDE) de hembras ovígeras de Cryphiops caementarius mantenidas en condiciones de laboratorio. 


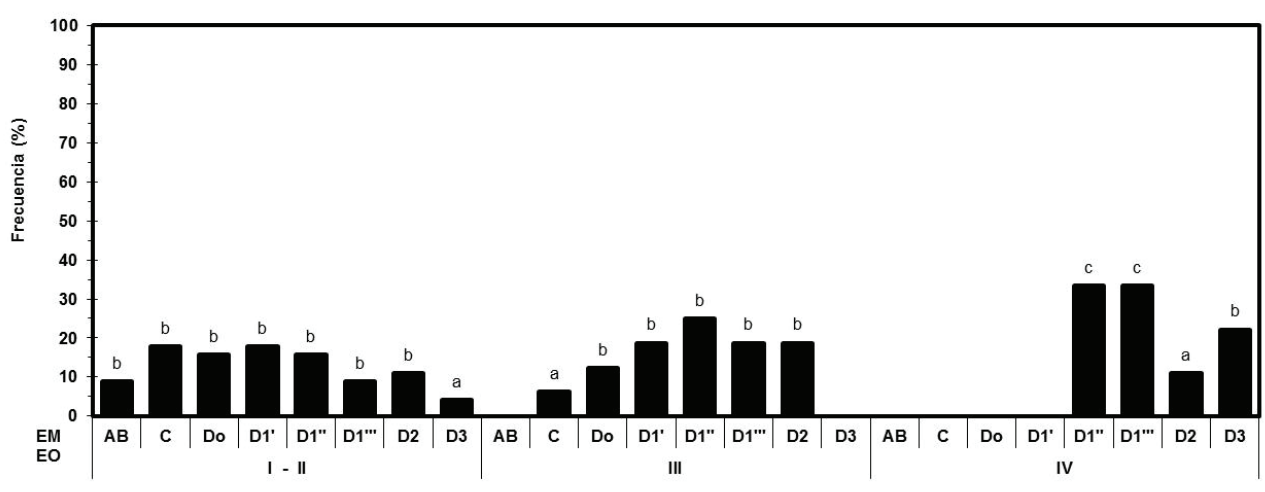

Figura 5. Frecuencia porcentual de la relación entre los estados de muda (EM) y los estados de maduración del ovario (EO) de hembras ovígeras de Cryphiops caementarius mantenidas en condiciones de laboratorio.

De acuerdo al estado de maduración del ovario de $C$. caementarius, dos tipos de muda fueron observados: la muda regular y la muda pre-apareamiento, determinadas por la ausencia y presencia de setas ovígeras en los pleópodos, respectivamente. Todas las hembras ovígeras procedentes del río que presentaron ovarios maduros realizaron muda pre-apareamiento en laboratorio, de igual manera lo hicieron la mitad del total de las hembras con ovarios en maduración intermedia; en ambos casos, las hembras desovaron al siguiente día y los ovarios post desove retornaron al estado inmaduro, permaneciendo hasta la siguiente muda que fue una muda regular. En cambio, las hembras ovígeras procedentes del río con ovarios inmaduros y la otra mitad del total de hembras en maduración intermedia, solo realizaron mudas regulares en laboratorio.

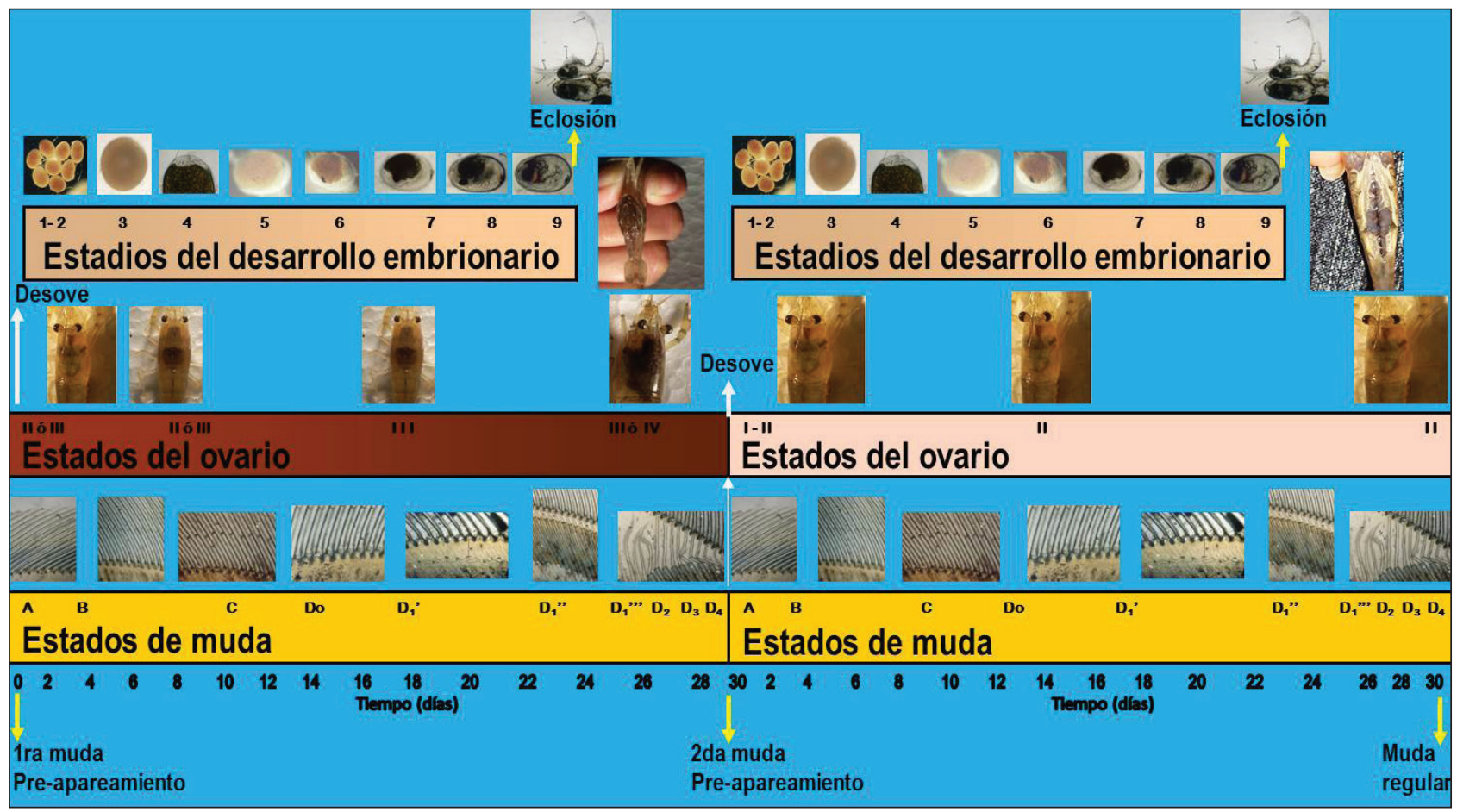

Figura 6. Resumen de la interrelación entre los estados de muda, los estados del ovario y los estadios del desarrollo embrionario de hembras ovígeras de Cryphiops caementarius. 
En base a los resultados obtenidos con las hembras ovígeras de $C$. caementarius procedentes del río Lacramarca, se propone una relación entre los estados del ciclo de muda, los estados del ovario y los estadios del desarrollo embrionario (Figura 6).

\section{DISCUSIÓN}

Los resultados del estudio determinaron que conforme avanzó el desarrollo de los embriones portados por las hembras de $C$. caementarius, que duró 23 días, también avanzaron los estados del ciclo de muda, que duró 30 días. Similar duración del ciclo de muda es reportado en la misma especie pero en hembras no ovígeras (Reyes et al., 2002), lo que demuestra que no hay inhibición del ciclo de muda, sino sincronización entre muda y reproducción en las hembras ovígeras, como es descrito para otros crustáceos (Sardá, 1987; Van Wormhoudt y Bellow-Humbert, 1996). Además, la eclosión de los embriones de las hembras ovígeras de la especie en estudio ocurrió cuando estas estuvieron en premuda $\mathrm{D}_{1}$ ( $55,6 \%$ en $\mathrm{D}_{1}{ }^{\prime \prime}, 25,9 \%$ en $\mathrm{D}_{1}^{\prime \prime \prime}$ y $14,5 \%$ en $\left.\mathrm{D}_{1}{ }^{\prime}\right)$, cuyas ecdisis se produjeron a los 3, 6 y 9 días, respectivamente. En E. asiatica, los embriones eclosionan cuando el estado de premuda de la hembra avanza hasta $\mathrm{D}_{1}$ (Gunamalai y Subramoniam, 2002).

La presencia de embriones en los pleópodos de las hembras no afectó la duración de su ciclo de muda; sin embargo, al compararlo con hembras no ovígeras de la misma especie (Reyes et al., 2002), se observó que después del desove las hembras permanecieron mayor tiempo (4 días más) en postmuda a expensas de la duración de la intermuda y la premuda, lo cual sugiere que las hembras se agotarían después del desove por lo que tardaron una semana en reponerse del estrés fisiológico, probablemente porque utilizaron las reservas energéticas para la muda, el desove y para el mantenimiento de la masa embrionaria. Este uso de las reservas energéticas se sustenta debido a que las hembras no ingirieron alimento durante la premuda tardía $\left(\mathrm{D}_{2}\right.$ y $\left.\mathrm{D}_{3}\right)$, la ecdisis y la postmuda temprana (A), como ya ha sido reportado en la especie (Reyes et al., 2002) y es común en crustáceos (Petriella, 1986; Sardá, 1987), por lo que depende solamente de las reservas almacenadas entre los estados $\mathrm{C}$ y $\mathrm{D}_{1}$. En $C$. crangon las reservas almacenadas en el hepatopáncreas son transportadas al ovario durante la maduración gonadal (Spaargaren y Haefner, 1994) y de igual manera sucede en $P$. muelleri (Díaz et al., 2003) para ser utilizadas en la reproducción.
La continuación de la maduración del ovario de las hembras ovígeras de $C$. caementarius hasta presentar ovarios maduros (en el $100 \%$ de hembras) y las de maduración intermedia (en el $50 \%$ de hembras), serían indicadores de la buena condición nutricional de los reproductores procedentes del río, tal como es evidenciado por Harrison (1990) en otros crustáceos. En este sentido, las hembras ovígeras deben haber realizado en el río un primer ciclo reproductivo y ya en laboratorio continuaron con el segundo ciclo reproductivo, es decir con la segunda maduración ovárica aun estando ovígeras. El desarrollo simultáneo de los ovarios con la incubación de los huevos sucede también en M. olfersi (Mossolin y Bueno, 2002) y M. amazonicum (Sampaio et al., 2007). Además, luego de la eclosión de los embriones, estos dos grupos de hembras realizaron el segundo desove, previa muda pre-apareamiento, y en esta vez sus ovarios retornaron al estado inmaduro como signo de agotamiento energético para no continuar otro ciclo reproductivo; ocurriendo luego una muda regular. Esta característica es observada en $C$. crangon (Spaargaren y Haefner, 1994) y lo que ocurre en todo crustáceo es una aceleración de la vitelogénesis en un solo ciclo de muda durante la incubación de la puesta (Van Wormhoudt y Below-Humbert, 1996), aun cuando mucha energía es invertida durante el desarrollo del ovario para la producción de vitelo (Sokolowicz et al., 2006).

En consecuencia, en estos dos grupos de hembras de C. caementarius hubo interrelación entre el desarrollo embrionario, la maduración ovárica y el ciclo de muda, y soportaron solo dos ciclos reproductivos sucesivos en laboratorio, aunque se desconoce lo que sucede en el ambiente natural, siendo probable que por influencia ambiental y nutricional una hembra se reproduzca continuamente durante la época reproductiva. En un mismo periodo reproductivo, el número de desoves de cada hembra varía en función de la especie de crustáceo; así, M. hainanense realiza uno o dos desoves (Mantel y Dudgeon, 2005), E. modestus realiza un mínimo de dos desoves (Oh et al., 2002), M. rosenbergii cuatro desoves (Cavalli et al., 2001) y P. xiphias hasta cinco o seis desoves (Guerao et al., 1994). En M. olfersi, M. amazonicum y A. scabra, las hembras tienen el potencial de producir sucesivos estados ovígeras durante su vida reproductiva (Mossolin y Bueno, 2002; Sampaio et al., 2007; Almeida et al., 2010).

Los resultados de la presente investigación demuestran por primera vez que no hay necesidad de que el ovario de las hembras ovígeras de $C$. caementarius 
se encuentre completamente maduro para que se produzca la segunda muda pre-apareamiento y luego otro desove, lo cual difiere de lo reportado por Moreno et al. (2012) para la misma especie, quienes consideran que el ovario debe alcanzar la madurez para que se produzca el desove. Al respecto, se observaron, en un $50 \%$ de hembras ovígeras con embriones en estadio 7 y con ovario en maduración intermedia, que después de la eclosión de los embriones estas hembras lograron desovar nuevamente en laboratorio estando aún con ovario en maduración intermedia, previa segunda muda pre-apareamiento. Este resultado indicaría el gran potencial reproductivo de la especie, siempre que se mantengan adecuadas condiciones ambientales y nutricionales en laboratorio.

Es probable que el ovario de $C$. caementarius en maduración intermedia haya tenido alguna influencia ambiental estacional y nutricional, como sucede normalmente en otros crustáceos cuando el ovario alcanza la madurez, como es el caso de P. xiphi (Guerao et al., 1994), M. rosenbergii (Cavalli et al., 2001), P. muelleri (Díaz et al., 2003), M. iheringi (Fransozo et al., 2004) y Nematopalaemon schmitti (Almeida et al., 2011). Sin embargo, el desove con esta condición del ovario (estado III) ocasionó menor tamaño de la masa embrionaria, lo cual es necesario tener en cuenta para trabajos relacionados con la fecundidad y el rendimiento reproductivo de la especie, toda vez que ello podría significar que hubo pérdida de huevos durante la incubación. En diversos crustáceos decápodos se reportan pérdida de los huevos durante la incubación debido a condiciones naturales, físico mecánicas, por infecciones bacterianas o por hongos (Cavalli et al., 2001; Oh et al., 2002).

En contraste con lo arriba expuesto, el hecho de que se observaran hembras ovígeras que durante todo el desarrollo de sus embriones, hasta la eclosión, mantuvieran sus ovarios inmaduros o algunas en maduración intermedia, es un indicador de la culminación del actual ciclo reproductivo, evidenciado porque la muda post eclosión fue una muda regular. Estos resultados están de acuerdo con Cavalli et al. (2001) en hembras de $M$. rosenbergii, cuyas mudas no necesariamente están asociadas con la reproducción. Por consiguiente, en este grupo de hembras existió solo interrelación entre el desarrollo de los embriones y el ciclo de muda. Además, la muda regular como signo de agotamiento de las reservas energéticas para otro ciclo reproductivo reforzaría lo mencionado anteriormente, relacionado con la condición nutricional de los animales para la reproducción. Por consiguiente, los resultados demuestran por primera vez la interrelación entre el ciclo de muda, el ciclo ovárico y el desarrollo embrionario en hembras ovígeras de $C$. caementarius procedentes del ambiente natural, siendo ello de importancia en el manejo de reproductores de la especie para diferentes fines.

\section{BIBLIOGRAFÍA}

Aiken, D.E. y S.L. Waddy. 1987. Molting and growth in crayfish: A review. Canadian Technical Report of Fisheries and Aquatic Science 1587: 1-34.

Almeida, A.O., E.C. Mossolin y J.R. Luz. 2010. Reproductive biology of the freshwater shrimp Atya scabra (Leach, 1815) (Crustacea: Atyidae) in Ilhéus, Bahia, Brazil. Zoological Studies 49(2): 243-252.

Almeida, A.C., V. Fransozo, G. Monteiro, M. Furlan, K.A. Nunez y A. Fransozo. 2011. Population structure and reproductive period of whitebelly prawn Nematopalaemon schmitti (Holthuis 1950) (Decapoda: Caridea: Palaemonidae) on the southeastern coast of Brazil. Invertebrate Reproduction and Development 55(1): 30-39.

Amaya, J. y A. Guerra. 1976. Especies de camarones de los ríos norteños del Perú y su distribución. Ministerio de Pesquería. Dirección de Investigación Científica y Tecnológica 24: 1-60.

Cavalli, R.O., P. Lavens y P. Sorgeloos. 2001. Reproductive performance of Macrobrachium rosenbergii female in captivity. Journal of the World Aquaculture Society 32(1): 60-67.

Damrongphol, P., N. Eangchuan y B. Poolsanguan. 1991. Spawning cycle and oocyte maturation in laboratorymaintained giant freshwater prawns (Macrobrachium rosenbergii). Aquaculture 95(3-4): 347-357.

Díaz, A.C., A.M. Petriella y J.L. Fenucci. 2003. Ciclo de muda y reproducción de la población del langostino Pleoticus muelleri (Crustacea, Penaeoidea) de Mar del Plata. Ciencias Marinas 29(3): 343-355.

Fukushima, M., G. Sifuentes, G. Saldaña, G. Castillo, J. Reyes y L. Shimokawa. 1982. Métodos limnológicos. Departamento de Ciencias Biológicas. Universidad Nacional de Trujillo. Perú. 188 p.

Fransozo, A., F.D. Rodrigues, F.A. Freire y R.C. Costa. 2004. Reproductive biology of the freshwater prawn Macrobrachium iheringi (Ortmann, 1897) (Decapoda: Caridea: Palaemonidae) in the Botucatu region, São Paulo Brazil. Nauplius 12(2): 119-126. 
Guerao, G., J. Pérez-Baquera y C. Ribera. 1994. Growth and reproductive biology of Palaemon xiphias Risso, 1816 (Decapoda: Caridea: Palaemonidae). Journal of Crustacean Biology 14(2): 280-288.

Gunamalai, V. y T. Subramoniam. 2002. Synchronisation of molting and oogenic cycles in a continuously breeding population of the sand crab Emerita asiatica on the Madras Coast, South India. Journal of Crustacean Biology 22: 398-410.

Gunamalai, V., R. Kirubagaran y T. Subramoniam. 2004. Hormonal coordination of molting and female reproduction by ecdysteroids in the mole crab Emerita asiatica (Milne Edwards). General and Comparative Endocrinology 138: 128-138.

Harrison, K.E. 1990. The role of nutrition in maturation, reproduction and embryonic development of decapod crustaceans: a review. Journal of Shellfish Research 9(1): 1-28.

Lee, D. O’C. y J.F. Wickins. 1997. Cultivo de crustáceos. Editorial Acribia. Zaragoza. España. 449 p.

Lip, G. B. 1976. Primera madurez sexual del camarón de río Cryphiops caementarius Molina, 1782 (Natantia, Palaemonidae) en el río Moche. Tesis de Bachiller, Universidad Nacional de Trujillo, Perú. 79 p.

Mantel, S.K. y D. Dudgeon. 2005. Reproduction and sexual dimorphism of the palaemonid shrimp Macrobrachium hainanense in Hong Kong streams. Journal of Crustacean Biology 25(3): 450-459.

Méndez, M. 1982. Claves de identificación y distribución de los langostinos y camarones (Crustacea: Decapoda) del mar y ríos de la costa del Perú. Boletín Instituto del Mar del Perú. 5:1-170.

Morales, M.C., M. Rivera, J. Meruane, C. Galleguillos y H. Hosokawa. 2006. Morphological characterization of larval stages and first juvenile of the freshwater prawn Cryphiops caementarius (Molina, 1782) (Decapoda: Palaemonidae) under laboratory conditions. Aquaculture 261: 908-931.

Moreno, J.E., C.A. Méndez, J.A. Meruane y M.C. Morales. 2012. Descripción histológica y caracterización de los estados de madurez gonadal de hembras de Cryphiops caementarius (Molina, 1782) (Decapoda: Palaemonidae). Latin American Journal of Aquatic Research 40(3): 668-678.

Mossolin E.C. y S.L.S. Bueno. 2002. Reproductive biology of Macrobrachium olfersi (Decapoda, Palaemonidae) in São Sebastião, Brazil. Journal of Crustacean Biology 22(2): 367-376.
Oh, C.W., H.Lip Suh, K.Y. Park, C.W. Ma, y H.S. Lim. 2002. Growth and reproductive biology of the freshwater shrimp Exopalaemon modestus (Decapoda: Palaemonidae) in a lake of Korea. Journal of Crustacean Biology 22(2): 357-366.

Petriella, A.M. 1986. Estudio sobre la fisiología de la muda del camarón Artemesia longinaris Bate. II Crecimiento y frecuencia de muda. Revista Latinoamericana de Acuicultura 29: 11-21.

Reyes W.E., M. Pilco y K. Olórtegui. 2002. Efecto de la ablación unilateral del pedúnculo ocular en la maduración ovárica y en el ciclo de muda de Cryphiops caementarius (Molina, 1872) (Decapoda, Palaemonidae) en laboratorio. Pp: 681-687. Comunicación Científica en el I Congreso Iberoamericano Virtual de Acuicultura. CIVA 2002 (http://www.civa2002.org).

Reyes, W.E. y H. Luján. 2003. Estados y subestados del ciclo de muda del camarón de río (Cryphiops caementarius Molina, 1872) (Crustacea: Decapoda: Palaemonidae). Pp: 808-817. Comunicación Científica en el II Congreso Iberoamericano Virtual de Acuicultura. CIVA 2003 (http:// www.civa2003.org).

Reyes, W.E., H. Luján, L. Moreno y M. Pesantes. 2009. Caracterización de estadios embrionarios de Cryphiops caementarius (Crustacea, Palaemonidae). SCIÉNDO 12(1): 55-67.

Sampaio C.M.S., R.R. Silva, J.A. Santos y S.P. Sales. 2007. Reproductive cycle of Macrobrachium amazonicum females (Crustacea, Palaemonidae). Brazilian Journal Biology 67(3): 551-559.

Sardá, F. 1987. La reproducción de los crustáceos. Fisiología: factores de regulación de la reproducción. Potencial reproductivo. pp: 251-295. En: J. Espinoza \& U. Labarta (Eds.). Reproducción en acuicultura. Edit. Industria Gráfica España, S.A. Madrid.

Sokolowicz, C. C., G. Bond-Buckup y L. Buckup. 2006. Dynamics of gonadal development of Aegla platensis Schmitt (Decapoda, Anomura, Aeglidae). Revista Brasileira de Zoologia 23 (4): 1153-1158.

Spaargaren, H. H. y P. A. Haefner 1994. Interactions of ovary and hepatopancreas during the reproductive cycle of Crangon crangon (L.).II. Biochemical relationships. Journal of Crustacean Biology 14(1): 6-19.

Van Wormhoudt A. y C. Bellow-Humbert. 1996. Bases biológicas de los cultivos de los crustáceos. Pp: 219-280. In G. Barnabé (Ed.). Bases biológicas y ecológicas de la acuicultura. Edit. Acribia, S.A. Zaragoza. España. 
Vegas, M., L. Ruiz, A. Vega y S. Sánchez. 1981. El camarón Cryphiops caementarius (Palaemonidae): desarrollo embriológico, contenido estomacal y reproducción controlada. Primeros resultados. Revista Latinoamericana de Acuicultura 19: 11-23.

Viacava, M., R. Aitken y J. Llanos. 1978. Estudio del camarón de río en el Perú. 1975-1976. Boletín de Instituto del Mar del Perú 3(35): 161-232.
Vinuesa, J.H., G.A. Lovrich y L.I. Comoglio. 1991. Maduración sexual y crecimiento de las hembras de centolla Lithodes santolla (Molina, 1782) en el canal de Beagle. Biota 7: 7-13.

Yépez, V. y R. Bandín. 1997. Evaluación del recurso camarón de río Cryphiops caementarius en los ríos Ocoña, Majes-Camaná y Tambo, Octubre 1997. Informe Progresivo del Instituto del Mar del Perú 77: 3-25.

Fecha de Recepción: 03/06/2014

Fecha de Aceptación: 27/10/2014

Para citar este artículo: Reyes, W. 2014. Interrelación del ciclo de muda, el ciclo ovárico y el desarrollo embrionario en hembras de Cryphiops caementarius Molina 1782

(Crustacea, Palaemonidae) Revista Intropica 9: 33 - 42 